BNL- 66148

INFORMAL REPORT

\title{
TWO NEW DUCT LEAKAGE TESTS
}

John W. Andrews

December 1998

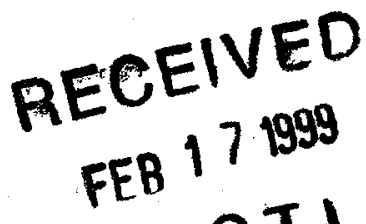 \\ OSTI}

Prepared for:

Office of Building Equipment

Office of Building Technology, State and Community Programs

United States Department of Energy

Washington, DC 20585

Energy Efficiency and Conservation Division

DEPARTMENT OF APPLIED SCIENCE

BROOKHAVEN NATIONAL LABORATORY

UPTON, LONG ISLAND, NEW YORK 11973 


\section{DISCLAIMER}

This report was prepared as an account of work sponsored by an agency of the United States Government. Neither the United States Government nor any agency thereof, nor any of their employees, nor any of their contractors, subcontractors, or their employees makes any warranty, express or implied, or assumes any legal liability or responsibility for the accuracy, completeness, or usefulness of any information, apparatus, product or process disclosed, or represents that its use would not infringe privately owned rights. Reference herein to any specific commercial product, process, or service by trade name, trademark manufacturer, or otherwise, does not necessarily constitute or imply its endorsement, recommendation, or favoring by the United States Government or any agency thereof. The views and opinions of authors expressed herein do not necessarily state or reflect those of the United States Government or any agency, contractor, or subcontractor thereof. 


\section{DISCLAIMER}

Portions of this document may be illegible in electronic image products. Images are produced from the best available original document. 
BNL- 66148

\section{TWO NEW DUCT LEAKAGE TESTS}

BY:

JOHN W. ANDREWS

DECEMBER 1998

Prepared for:

Office of Building Equipment

Office of Building Technology, State and Community Programs United States Department of Energy

Washington, DC 20585

Under Contract No. DE-AC02-98CH10886

Brookhaven National Laboratory

Upton, NY 11973-5000 


\begin{abstract}
Two variations on the tests for duct leakage currently embodied in ASHRAE Standard 152P (Method of Test for Determining the Design and Seasonal Efficiencies of Residential Thermal Distribution Systems) are presented. Procedures are derived for calculating supply and return duct leakage to/from outside using these new variations. Results of these tests are compared with the original ones in Standard 152P on the basis of data collected in three New York State homes.
\end{abstract}




\section{TABLE OF CONTENTS}

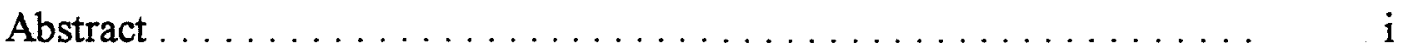

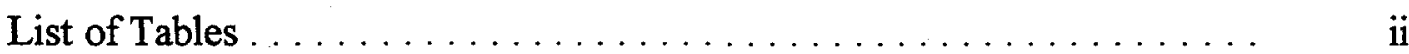

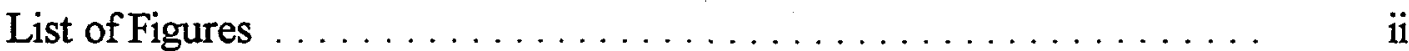

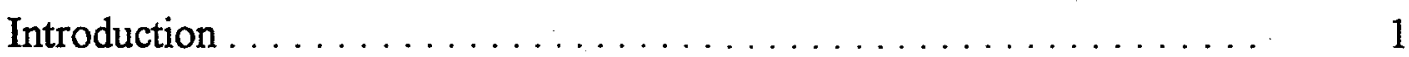

Description of the Hybrid Test Procedure $\ldots \ldots \ldots \ldots \ldots \ldots \ldots \ldots, 2$

Calculation Procedure for the Hybrid Test $\ldots \ldots \ldots \ldots \ldots \ldots \ldots \ldots$

The Blocked-Supply House Pressure Test $\ldots \ldots \ldots \ldots \ldots \ldots . \ldots$

Advantages and Disadvantages of the Various Tests $\ldots \ldots \ldots \ldots \ldots .7$

Some Test Results $\ldots \ldots \ldots \ldots \ldots \ldots \ldots \ldots \ldots \ldots \ldots \ldots, 8$

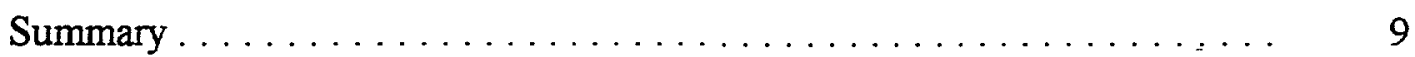

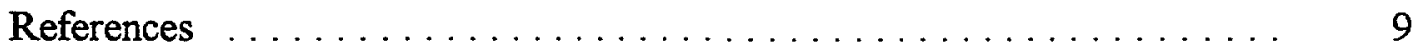

\section{LIST OF FIGURES}

1. Pressure Relationships in Ducts . . . . . . . . . . . . . . 10

2. Duct Leakage Results, One-Story House, $730 \mathrm{ft}^{2}$, Ducts in Unconditioned Basement $\ldots \ldots \ldots \ldots \ldots \ldots \ldots .10$

3. Duct Leakage Results, Two-Story House, $1115 \mathrm{ft}^{2}$, Ducts in Unconditioned Basement $\ldots \ldots \ldots \ldots \ldots \ldots \ldots \ldots, 11$

4. Duct Leakage Results, One-Story House, $1500 \mathrm{ft}^{2}$, Ducts in Unconditioned Basement

\section{LIST OF TABLES}

1. Advantages and Disadvantages of Four Duct-Leakage Tests . . . . . . 7 


\section{INTRODUCTION}

The American Society of Heating, Refrigerating, and Air-Conditioning Engineers (ASHRAE) is developing Standard 152P, Method of Test for Determining the Design and Seasonal Efficiencies of Residential Thermal Distribution Systems. [ASHRAE 1998] For forced-air distribution systems, the key quantities to be measured are the air leakage rates (to/from the outside) of the supply and return portions of the duct system. The standard embodies two alternative ways of determining these duct leakage rates. Several criticisms of these tests have recently come to the fore. These criticisms fall into two areas. One concerns the reliability of the tests, including issues of reproducibility and accuracy. The other concerns the possibility that the level of effort required to do a test may be excessive.

The more traditional of the duct leakage tests is the fan pressurization test. It involves pressurizing (or depressurizing) the house to $25 \mathrm{~Pa}$ with a blower door and simultaneously bringing the supply (or the return) duct system to the same pressure with a small version of the blower door fan which is referred to in ASHRAE Standard 152P as a "fan/flowmeter." To do this, the supply and return systems need to be separated by inserting a temporary barrier, generally at the return plenum outlet to the heating/cooling unit, and also sealing all the registers, except the one to which the fan/flowmeter is attached. The cfm reading of the fan/flowmeter is converted to a leakage $c f m$ under normal operation by multiplying this reading by the factor $(\Delta \mathrm{P} / 25)^{0.6}$, where $\Delta \mathrm{P}$ is a measured value representing an average operating pressure in the duct and the 0.6 is a standard value for the exponent in the air flow vs. pressure relationship.

The house pressure test involves repeated measurements of the pressure difference between the inside and the outside of the house envelope under three operating conditions of the system fan-1) on, 2) off, and 3) on with the return register partially blocked. These three "house pressures" are denoted by the symbols $\Delta \mathrm{P}_{\text {on }}, \Delta \mathrm{P}_{\text {off }}$, and $\Delta \mathrm{P}_{\mathrm{RB}}$, respectively. During the fan-on periods (with return registers open and blocked) pressures in the supply and return ducts are also measured.

At least two major criticisms of each test have been made. For the fan pressurization duct leakage test these are: 1) it tends to be quite time-consuming (two to three hours for a crew of two); and 2 ) it is not clear a priori what pressure should be used as the assumed "operating pressure" in the $(\Delta \mathrm{P} / 25)^{0.6}$ conversion referred to above. Presumably it should be a static pressure at the point in the duct where most of the leaks are, or some averaged value if the leaks are distributed, but one generally doesn't know where the leaks are when doing the test. Two duct systems that tested identically might have very different actual leakage rates if one system's leaks are mostly near the plenum (where the pressure difference across the duct surface is highest) while the other's are mostly in the register boots (where the pressure difference is low).

The house pressure test was developed in part to provide a faster way of assessing duct leakage, and it is in fact much quicker and easier to do than the fan pressurization test (an hour or less for a single tester). The two major criticisms of the house pressure test are, therefore, in the area of reliability: 1) its duct leakage results tend to have a lot of random uncertainty, especially on the supply side; and 2) the assumption concerning the vertical distribution of envelope air leakage may be violated to an unknown extent in a significant number of cases. 
The purpose of this discussion is to propose modifications to both of these tests that can mitigate and perhaps largely overcome these criticisms. The proposed alteration to the fan pressurization duct leakage test is to pressurize the duct system as a whole (rather than the supply and return systems separately) and to borrow the register-unblocked portion of the house pressure test to obtain an estimate of the leakage split between the supply and return ducts. The proposed altered test will be called the hybrid test, while the traditional protocol will continue to be referred to as the fan pressurization test.

The proposed alteration to the house pressure test is to partially block the supply registers rather than the return(s) at the point in the test where blocking registers is required. This altered test will be called the blocked-supply house pressure test, while the traditional protocol will be called the blocked-return house pressure test.

\section{DESCRIPTION OF THE HYBRID TEST PROCEDURE}

The hybrid test is described more completely as follows. Like the two-sided fan pressurization test, it uses a fan/flowmeter, but rather than testing the supply and return duct systems separately, it only requires one test, of the whole duct system. In addition to cutting the number of tests in half, it will usually save even more time because no barrier is needed between the supply and return ducts (a big plus!) and in almost all cases the fan/flowmeter can be attached to the duct system at the fan access opening, generally the most convenient location. Instead of directly measuring the supply- and return-side leakage coefficients, the hybrid test relies on the least controversial and easiest-to-do portion of the house pressure test--the part with unblocked registers--to help sort out how much of the leakage is on each side.

A summary of the protocol for this test, then, is as follows:

- Truncated house pressure test: run a plastic tube between the conditioned space and the attic. Open interior doors and close exterior doors. Measure the pressure difference between the house and the attic with the system fan on and with the fan off in three complete cycles of 10 five-second readings with fan on and 10 with fan off, for a total of 30 in each condition.

- Truncated fan-pressurization test: install a blower door in an exterior doorway and a fan/flowmeter at the fan access opening of the furnace or heat pump. Seal all registers. Use the blower door to measure the envelope CFM25 with registers sealed. (This is used with the house pressures.) With the house still pressurized to $25 \mathrm{~Pa}$, use the fan/flowmeter to bring the duct pressure equal to that in the house. Read the CFM25 for the duct system to outside from the calibration chart on the fan/flowmeter.

- Operating pressures in the ducts: unseal all registers and remove test equipment. With the system fan on, measure the return plenum static pressure with respect to the house and take a pressure pan reading (with respect to house) at each supply register. 
The above protocol will provide all the information needed to calculate supply and return leakage to/from outside.

At this point, some general comments are in order. First, Standard 152 currently specifies that for the fan pressurization test the supply ducts (and the house) should be pressurized while the return ducts (and the house) should be depressurized. For the hybrid test, obviously, one has to do one or the other. Also, the point within the ducts whose pressure is to be equalized with that of the house is specified, for the supply-side test, as "at a supply register other than that to which the fan/flowmeter is connected." On the return side, no specific test point is specified. For the hybrid test, one would like to have the entire duct system at the same pressure, which may be difficult if the supply ducts are leaky, as then there is likely to be a pressure drop across the system fan. Pending further work on this point, it is suggested that pressure taps be placed in the supply and return plenums and that these be ganged together with plastic tubes leading to a tee, whose third end is then connected to the input port of a digital manometer (the reference port being connected to a tube leading into the conditioned space). This should give a good average static pressure in the supply and return ducts. (Any research project evaluating this test should also measure the static pressures at several of the sealed supply and return registers to quantify the pressure variation over the system.) Finally, for the hybrid test it is not clear a priori whether the ducts (and the house) should be pressurized or depressurized, but this discussion will assume that they are pressurized.

\section{CALCULATION PROCEDURE FOR THE HYBRID TEST}

Four input quantities are needed to calculate the supply and return leakage to/from outside using the hybrid duct leakage test:

$\mathrm{Q}_{\text {sleak }+ \text { treak }}$ the algebraic sum of supply $(+)$ and return $(-)$ leakage to/from outside, calculated using Equation D3 of draft Standard 152P. This equation in turn relies on three quantities: $C_{\text {env }}$ the house envelope flow coefficient; $\Delta P_{\text {on }}$, the house-attic pressure difference with the system fan on; and $\Delta \mathrm{P}_{\text {off }}$, the house-attic pressure difference with the system fan off. It is recommended that $C_{\mathrm{env}}$ be measured with the registers sealed (they have to be sealed anyway in this test), and that the correction for unsealed registers in Equations D11 and D12 not be applied. Also, it is not possible to apply the neutral level shift correction of equations D9 and D10 without knowing supply and return leakage separately. This could be done by iteration, but this correction is usually minor and it can be shown that in the hybrid test it will be even more minor, and in my tentative judgment, not worth worrying about in this calculation.

$\mathrm{C}_{\text {tot }} \quad$ the air leakage flow coefficient for the whole duct system. This is calculated using the usual leakage flow equation $\mathrm{Q}=\mathrm{C} \Delta \mathrm{P}^{\mathrm{n}}$. Following Standard 152P, we measure the leakage flow at $25 \mathrm{~Pa}$ and assume $\mathrm{n}=0.6 . \mathrm{C}_{\text {tot }}$ is then the measured leakage cfm at $25 \mathrm{~Pa}$ divided by $25^{0.6}(=6.90)$.

$\Delta \mathrm{P}_{\text {sup }} \quad$ Supply and return duct operating pressures, measured per Standard 152.

$\Delta \mathrm{P}_{\text {ret }} \quad$ The supply operating pressure is the average of pressure pan readings and the return operating pressure is one-half the static pressure at the plenum. 
The necessary equations can then be developed fairly simply, as two equations in the unknowns $\mathrm{C}_{\text {sup }}$ and $\mathrm{C}_{\mathrm{ret}}$, the supply and return duct air leakage flow coefficients. One equation is simply the statement that these two quantities have to add up to $\mathrm{C}_{\text {tot }}$ :

$$
C_{\text {sup }}+C_{\text {ret }}=C_{\text {tot }}
$$

while the other is obtained by representing the supply and return leakage rates in terms of flow coefficients and operating pressures:

$$
C_{\text {sup }} \Delta P_{\text {sup }}^{n}-C_{\text {ret }} \Delta P_{\text {ret }}^{n}=Q_{\text {sleak }+ \text { rleak }}
$$

with $\mathrm{n}$ assumed to equal 0.6 in Standard 152P.

Solving Equations 1 and 2 for $\mathrm{C}_{\text {sup }}$ and $\mathrm{C}_{\text {ret }}$ yields:

$$
\begin{gathered}
C_{\text {sup }}=\frac{Q_{\text {sleak }+ \text { rleak }}+C_{\text {tot }} \Delta P_{\text {ret }}^{n}}{\Delta P_{\text {sup }}^{n}+\Delta P_{\text {ret }}^{n}} \\
C_{r e t}=\frac{C_{\text {tot }} \Delta P_{\text {sup }}^{n}-Q_{\text {sleak }+ \text { rleak }}}{\Delta P_{\text {sup }}^{n}+\Delta P_{\text {ret }}^{n}}
\end{gathered}
$$

To go from leakage flow coefficients to leakage flows requires more step:

$$
\begin{gathered}
Q_{s}=C_{\text {sup }} \Delta P_{\text {sup }}^{n}=\frac{Q_{\text {sleak }+ \text { rleak }} \Delta P_{\text {sup }}^{n}+C_{\text {tot }} \Delta P_{\text {ret }}^{n} \Delta P_{\text {sup }}^{n}}{\Delta P_{\text {sup }}^{n}+\Delta P_{\text {ret }}^{n}} \\
Q_{r}=C_{\text {ret }} \Delta P_{\text {ret }}^{n}=\frac{C_{\text {tot }} \Delta P_{\text {sup }}^{n} \Delta P_{\text {ret }}^{n}-Q_{\text {sleak }+ \text { rleak }} \Delta P_{\text {ret }}^{n}}{\Delta P_{\text {sup }}^{n}+\Delta P_{\text {ret }}^{n}}
\end{gathered}
$$

where $Q_{s}$ and $Q_{r}$ are the desired supply and return leakage rates to/from the outside.

\section{THE BLOCKED-SUPPLY HOUSE PRESSURE TEST}

The original formulation of the house pressure test includes a step in which the return register(s) are progressively blocked with a piece of newspaper or cardboard, until the pressure in the return duct drops to $-100 \mathrm{~Pa}$. The ratio of the return-duct pressure with the partial blockage, denoted as $\Delta \mathrm{P}_{\text {retkB }}$, to the return-duct pressure with open registers, denoted as $\Delta \mathrm{P}_{\text {ret }}$ is raised to the 0.6 
power with the result defined as a new parameter $Z$. (This had been called--rather more obviously--R in Standard 152, but then someone noticed that this symbol was already taken for thermal resistance, so $\mathrm{Z}$ was chosen instead. A similar parameter involving pressures in the supply ducts is given the symbol $S$ in the draft ASHRAE standard.)

When the house pressure test was first conceived, it was assumed that this parameter would not be a strong function of the point in the return duct where the pressures were measured, as long as they were both measured at the same point. It was also assumed that the equations for leakage would not be unduly sensitive to variations in this parameter. Unfortunately, neither of these assumptions has turned out to be correct.

The reason that $Z$ depends on the point in the return duct where the pressures are measured is illustrated in Figure 1. The solid line presents a hypothetical (but typical) graph of pressure in a straight return duct as a function of distance from the register. The points $\mathrm{A}, \mathrm{B}$, and $\mathrm{C}$ represent measurements made at distances that are $1 / 4,1 / 2$, and $3 / 4$ of the way from the register to the plenum. There is a sudden pressure rise at the fan, and then a fall in pressure on the supply side until a register is reached. Generally there will be small pressure drops at the registers, on the order of 5 to $10 \mathrm{~Pa}$.

Although it is true that the instructions specify that the return-pressure measurements should be made at the midpoint of the duct, this is often difficult to achieve in practice. Because of bends in the return duct, the technique of stuffing a plastic tube through the register often results in the tube's coiling up at the first bend, which may be nowhere near the midpoint of the duct. Careful researchers will note when this difficulty is likely and surmount it by drilling a small hole into the return duct at the midpoint and inserting a probe from the outside, but even in this case it is often difficult to determine exactly where the midpoint is. In a complex system with several return registers, the concept of a "midpoint" may not even be well defined.

The dashed line in Figure 1 marked "blocked return" presents the pressure graph for a partially blocked return register. This line has less slope than the solid line because, with the return register partly blocked, there will be less air flow through the return duct, and therefore less pressure drop from the register to the plenum. The blockage of the return register will, however, produce a large immediate pressure drop across this register.

As one can see from this diagram, the ratio of blocked-return to open-register pressures in the return duct will depend quite strongly on where in the return duct the measurements are taken. This ratio will be greatest at point $\mathrm{A}$ and least at point $\mathrm{C}$.

The result of this variation in return-duct pressure ratios is that in many situations the uncertainty in the leakage rates can be unacceptably large. This is particularly true for supply-duct leakage in systems where retum leakage is dominant.

To get around this problem, it is proposed that rather than partially blocking the return register(s), the supply registers instead be partially blocked. Admittedly, this will be somewhat more timeconsuming than blocking the return(s), because there are usually more supply registers than 
returns. However, if this change is made the ratio of blocked to unblocked return-duct pressures will be nearly the same regardless of where in the return duct the measurements are made.

The reason for this can be seen by looking at the dashed line marked "blocked supply" in Figure 1. When the supply registers are partially blocked, the air flow through the system will be reduced, just as it is when one blocks the return. As in the blocked-return case, this will result in a lower pressure drop between the return register and the return plenum. The difference is that now there is no large initial pressure drop at the return register, because it is not blocked. The ratio of blocked-supply to open-register pressures in the return duct will be the same regardless of where in the return duct the measurement is made (although the measurement errors should be smallest, on a percentage basis, if the readings are taken at or near the downstream end).

One concern in making this change is that the problem with the duct pressure measurements on the return side might just be transferred to the supply side. After all, with blocked supply registers, there is now as large a pressure drop across the supply registers as there was across the returns in the blocked-return house pressure test. The situations are not the same, however, because of the different manner in which the pressures are measured. On the return side, the exact spot where the measurement is made is a critical variable. On the supply side, the measurements are always made at a register (with a pressure pan), so where in the duct the measurement is made never becomes an issue.

There are, nevertheless, many supply registers to choose from, and it would seem possible that the results might depend strongly on which register one uses. That's a legitimate worry, one that we investigated recently in three houses, the data on which are discussed below. A priori, however, there is some reason to believe that this will be less of a problem, because an error analysis indicates that the results tend to be somewhat less sensitive to the supply-side pressure ratio than they are to the return-side pressures. Also, if need be, the test could require that data from two or three supply registers be averaged to minimize the uncertainty from this source. The added effort would only add a couple of minutes to the test procedure.

Another question relates to whether the calculation procedure needs to be altered for the blockedsupply case. An analysis of the derivation of these equations indicates that the same math goes through regardless of whether you block the supply registers or the returns (with the possible exception of a usually minor correction for change in the neutral-pressure level in the house envelope). Although the math is the same, the character of the inputs will be different. These differences can be summarized as follows:

- $\quad$ For blocked-return tests, $Z>1$. For blocked-supply tests, $Z<1$.

- $\quad$ For blocked-return tests, $\mathrm{S}<1$. For blocked-supply tests, $\mathrm{S}>1$.

- For blocked-return tests, the house pressure with fan on and return blocked $\left(\Delta \mathrm{P}_{\mathrm{RB}}\right)$ will be algebraically greater than the house pressure with fan on and return open $\left(\Delta \mathrm{p}_{\mathrm{on}}\right)$, i.e., $\Delta \mathrm{P}_{\mathrm{RB}}$ will be to the right of $\Delta \mathrm{p}_{\text {on }}$ if both are plotted on an X-axis. For blocked supply tests, the house pressure with fan on and supply blocked (which may be called $\Delta \mathrm{P}_{\mathrm{SB}}$ ) will be algebraically less than $\Delta \mathrm{p}_{\text {on }}$. 
The same spreadsheet can be used for both kinds of tests. In the blocked-supply case, simply insert the blocked-supply data in the same positions where the corresponding blocked-return data are called for.

\section{ADVANTAGES AND DISADVANTAGES OF THE VARIOUS TESTS}

Table 1 summarizes the advantages and disadvantages of four tests--fan pressurization, blockedreturn house pressure, blocked-supply house pressure, and hybrid. These are assessed with respect to both time and difficulty of doing the test (logistics) and reproducibility and accuracy (expected error). In each box will be one of the following symbols: [-], [0], or [+]. The [-] indicates that with respect to the issue dealt with on this row of the table, the test in question is the least advantageous of the four; $[+]$ indicates that it is the most advantageous, while [o] indicates an intermediate level of goodness. Two tests may get a $[+]$ or $[-]$ if they are both about equal in respect to the issue under consideration.

Table 1. Advantages and Disadvantages of Four Duct-Leakage Tests

\begin{tabular}{|l|l|l|l|}
\hline Fan Pressurization & $\begin{array}{l}\text { House Pressure } \\
\text { (Blocked Return) }\end{array}$ & $\begin{array}{l}\text { House Pressure } \\
\text { (Blocked Supply) }\end{array}$ & Hybrid \\
\hline \multicolumn{3}{|c|}{ Considerations relating to difficulty in performing the test. } \\
\hline $\begin{array}{l}\text { Supply/-return barrier } \\
\text { required[-] }\end{array}$ & $\begin{array}{l}\text { No barrier needed } \\
{[+]}\end{array}$ & $\begin{array}{l}\text { No barrier needed } \\
{[+]}\end{array}$ & $\begin{array}{c}\text { No barrier needed } \\
{[+]}\end{array}$ \\
\hline $\begin{array}{l}\text { Needs 2 fan/flow- } \\
\text { meter tests [-] }\end{array}$ & $\begin{array}{l}\text { Needs no fan/flow- } \\
\text { meter tests [+] }\end{array}$ & $\begin{array}{l}\text { Needs no fan/flow- } \\
\text { meter tests [+] }\end{array}$ & $\begin{array}{l}\text { Needs one fan/flow- } \\
\text { meter test [o] }\end{array}$ \\
\hline $\begin{array}{l}\text { Needs no house } \\
\text { pressure tests [+] }\end{array}$ & $\begin{array}{l}\text { Needs all house } \\
\text { pressure tests [-] }\end{array}$ & $\begin{array}{l}\text { Needs all house } \\
\text { pressure tests [-] }\end{array}$ & $\begin{array}{l}\text { Needs some house } \\
\text { pressure tests [o] }\end{array}$ \\
\hline \multicolumn{2}{|c|}{ Considerations relating to reproducibility and/or accuracy of the test. } \\
\hline $\begin{array}{l}\text { No dependence on } \\
\text { envelope air leakage } \\
{[+]}\end{array}$ & $\begin{array}{l}\text { Linear dependence on } \\
\text { envelope air leakage } \\
{[-]}\end{array}$ & $\begin{array}{l}\text { Linear dependence on } \\
\text { envelope air tightness } \\
{[-]}\end{array}$ & $\begin{array}{l}\text { Sub-linear depen- } \\
\text { dence on envelope air } \\
\text { leakage [o] }\end{array}$ \\
\hline $\begin{array}{l}\text { Sensitive to errors in } \\
\text { duct pressures } \\
{[0]}\end{array}$ & $\begin{array}{l}\text { Highly sensitive to } \\
\text { errors in duct pres- } \\
\text { sures, especially on } \\
\text { the return side[-] }\end{array}$ & $\begin{array}{l}\text { Sensitivity to duct } \\
\text { pressures much } \\
\text { reduced, relative to } \\
\text { blocked return [+] }\end{array}$ & $\begin{array}{l}\text { Sensitivity to duct } \\
\text { pressures } \sim 1 / 2 \text { that of } \\
\text { fan pressurization test } \\
{[+]}\end{array}$ \\
\hline $\begin{array}{l}\text { No dependence on } \\
\text { house pressures } \\
{[+]}\end{array}$ & $\begin{array}{l}\text { Depends on 3 house } \\
\text { pressures: fan-on, } \\
\text { fan-off, and return- } \\
\text { blocked [-] }\end{array}$ & $\begin{array}{l}\text { Depends on 3 house } \\
\text { pressures: fan-on, } \\
\text { fan-off, and supply- } \\
\text { blocked [-] }\end{array}$ & $\begin{array}{l}\text { Depends on 2 house } \\
\text { pressures: fan-on and } \\
\text { fan-off [o] }\end{array}$ \\
\hline
\end{tabular}


Knowledgable people may have differences of opinion concerning the relative weights that should be assigned to these advantages and disadvantages. It is clear, however, that both house pressure tests and the hybrid test have well-defined advantages over fan pressurization in terms of ease of use. The blocked-supply house pressure test offers significant reproducibility advantages over the blocked-return version of the test. While the hybrid test may or may not be more accurate, on average, than the fan-pressurization test, it does have the advantage of spreading its vulnerabilities around, with less dependence on the duct pressures than fan-pressurization and less dependence on house pressures and envelope leakage than the house pressure tests.

\section{SOME TEST RESULTS}

Figures 2-4 show results of the four tests for three houses on Long Island, presented in the chronological order in which the tests were conducted. The histograms represent house pressure test results, obtained as follows. A protocol exercising both the blocked-return and blockedsupply versions of the test was run using four different measurement points in the return duct, six different supply registers at which pressure-pan measurements were taken, and three complete runs of the protocol. The same open-register data were used for both the blocked-return and the blocked-supply calculations. Thus, $4 \times 6 \times 3=72$ different values of supply and return leakage to/from outside were obtained for each house. These are plotted as histograms on the charts, with solid bars representing data from the two best measurement points in the return duct (nearest the midpoint for the blocked-return test and farthest downstream for the blocked-supply test) and the gray bars representing the remainder of the data. The arrows superimposed on the top charts for each house show the leakage values to/from outside obtained for the fan pressurization test and the hybrid test. Because the data were taken before the hybrid test was conceived, it was necessary to simulate a measured value for $C_{\text {tot }}$ by adding the values of $C_{\text {sup }}$ and $C_{\text {ret }}$ obtained in the separate fan pressurization measurements, and combining this with the average $Q_{\text {sleak }+ \text { leak }}$ value from the house pressure tests, as a way of approximating what would have been obtained in a straightforward hybrid test. (Note that since $\mathrm{Q}_{\text {steaktriteak }}$ is obtained using only the open-register house pressures and not the blocked-register house pressures or the pressures in the ducts, its value is the same for all house pressure tests within one complete run of the protocol described above. In other words, even though 72 values of supply and return leakage were obtained for each house pressure test, these were based on only three values of $\mathrm{Q}_{\text {sleak }+ \text { teak }}$ one for each run of the protocol, and these three values showed very good repeatability, the average deviation from each house's mean value being $<15 \mathrm{cfm}$.)

In House 14, the hybrid test and the fan/flowmeter test both showed excellent agreement with the blocked-supply house pressure test on the return side, and good agreement on the supply side. As this house has only six supply registers, blocking one of them surely raises the operating pressure in the supply ducts, so one would expect some upward bias on the supply leakage for both of the tests using the fan/flowmeter. Repeatability of results for the blocked-return house pressure test was not good. The best one could say is that it provided a lower limit for the return-duct leakage, but it gives essentially no information on supply-duct leakage. This is consistent with expectations from our error analysis, which predicts poor repeatability of supply-duct leakage values in systems with dominant return leakage. 
In House 1, the hybrid test agreed excellently with the blocked-supply house pressure test on both the supply and return sides. The fan pressurization (fan/flowmeter) test agreed somewhat less well on the return side. The blocked-return house pressure test fared somewhat better in this house, in which the duct leakage is close to balanced, but there is still a factor-of-three uncertainty in the supply leakage value.

In House 9, there is reason to believe that our fan/flowmeter measurement of the return leakage may have been high. Certainly the value of return leakage given by the fan/flowmeter test was an unusually large fraction of the $\sim 1300 \mathrm{cfm}$ system fan flow rate. When the same numbers were run through the hybrid test algorithm, the agreement on the return side improved drastically, at the cost of somewhat less good agreement on the supply side. As in House 14, the blocked-return house pressure test provided a lower limit on return leakage and no information on the supply side. Like House 14, House 9 is strongly return-leak-dominant (based on the other three tests), so this result is not surprising.

\section{SUMMARY}

The hybrid test is not quite as easy to do as the house pressure test, but it will be far faster than the standard fan pressurization test. It should be more repeatable in situations where the return ducts have many small registers, since there is no need to pressurize the return duct separately. The blocked-supply house pressure test appears to offer distinct advantages over the blockedreturn version, with only a small increase in the time needed to run the test. Further tests by other researchers should be done.

\section{REFERENCES}

ASHRAE 1998. Standard 152P: Method of Test for Determining the Design and Seasonal Efficiencies of Residential Thermal Distribution Systems. American Society of Heating, Refrigerating, and Air-Conditioning Engineers, Inc., Atlanta, GA. 
RETURN SIDE

SUPPLY SIDE

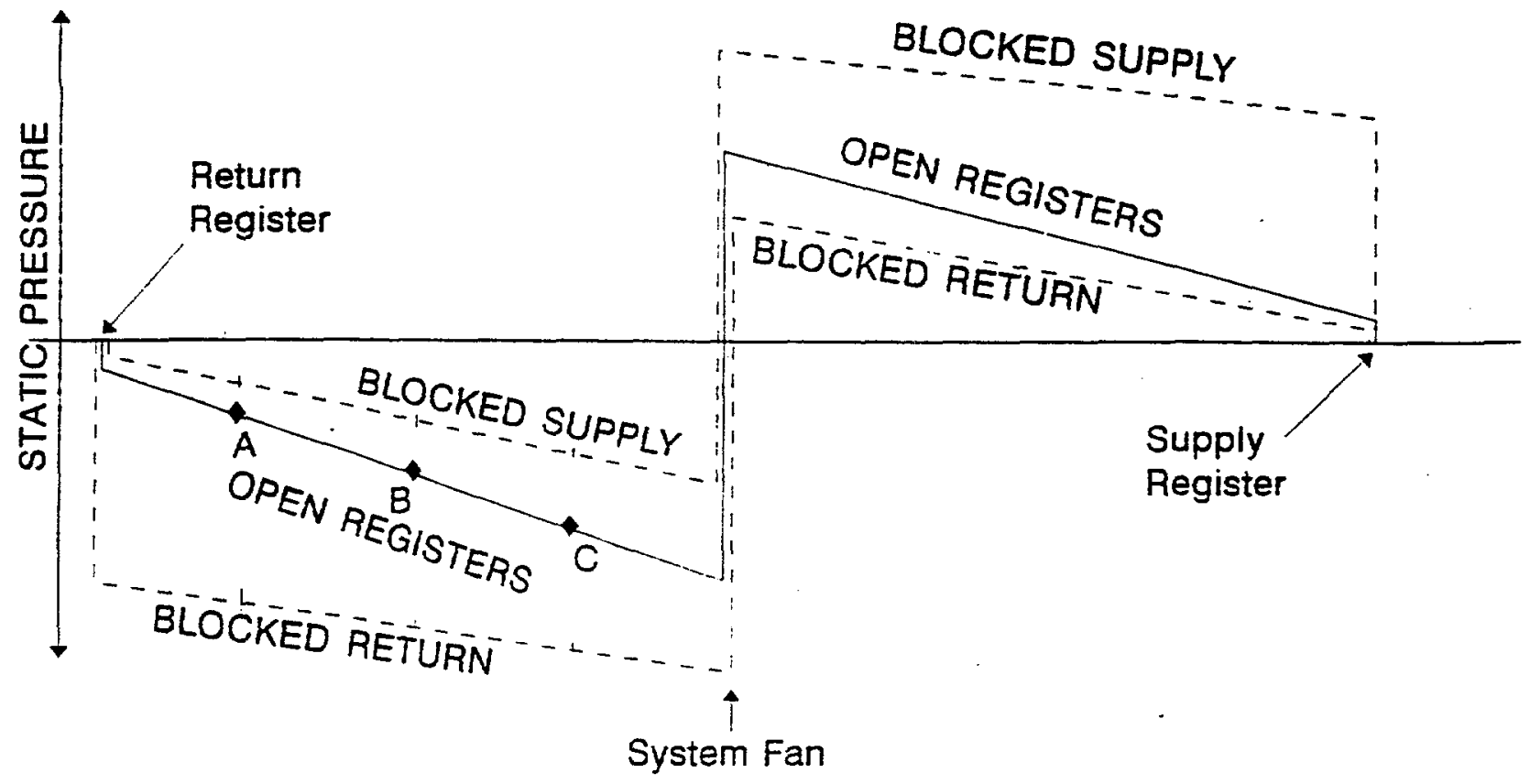

Figure 1. Pressure Relationships in Ducts
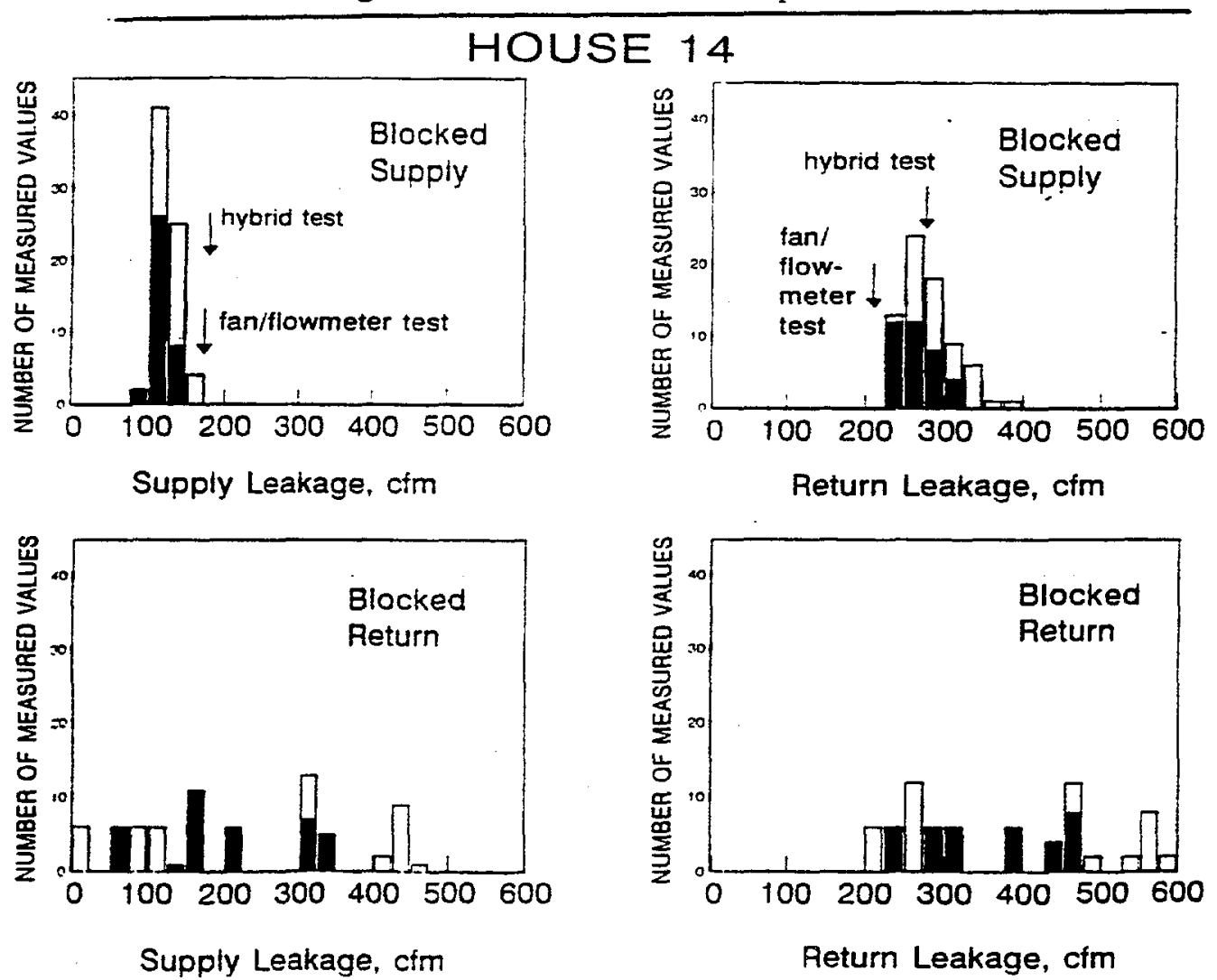

Figure 2. Duct Leakage Results, One-Story House, $730 \mathrm{ft}^{2}$, Ducts in Unconditioned Basement. 
HOUSE 1
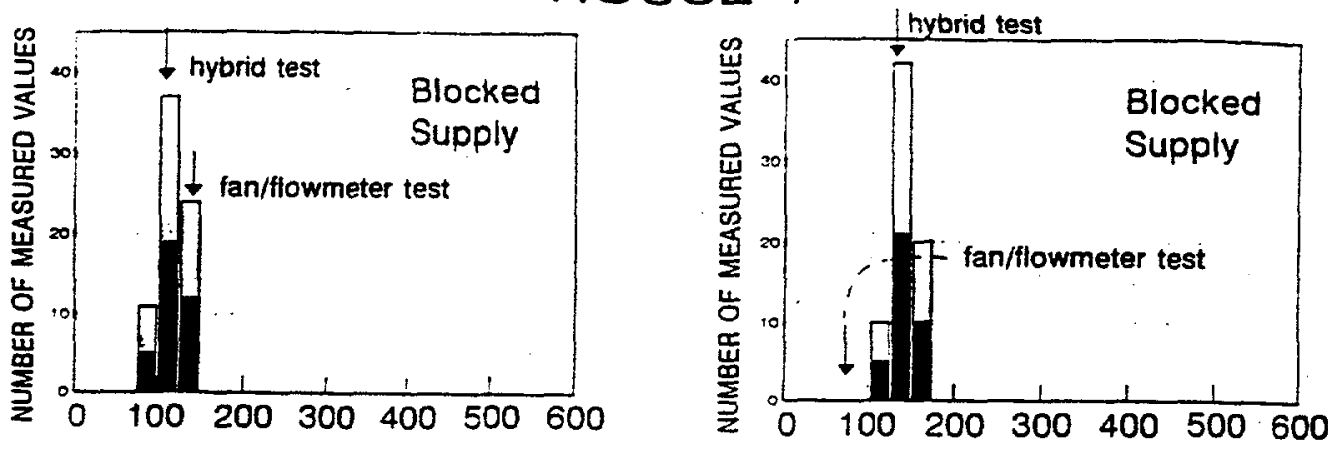

Supply Leakage, cfm

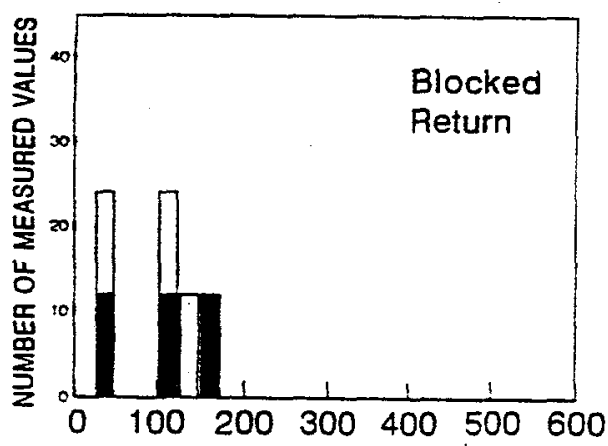

Supply Leakage, cfm

Return Leakage, ctm

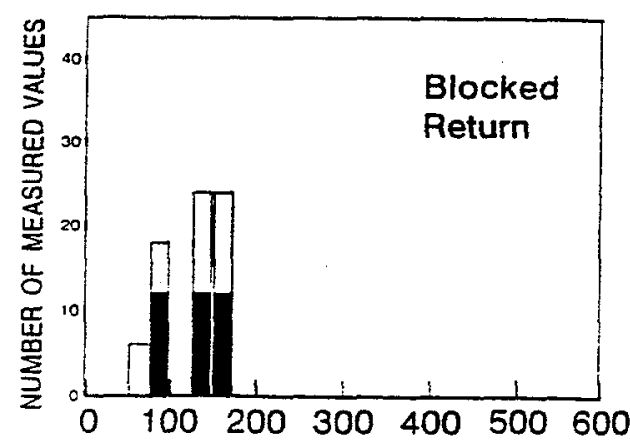

Return Leakage, cfm

Figure 3. Duct Leakage Results, Two-Story House, $1115 \mathrm{ft}^{2}$, Ducts in Unconditioned Basement.

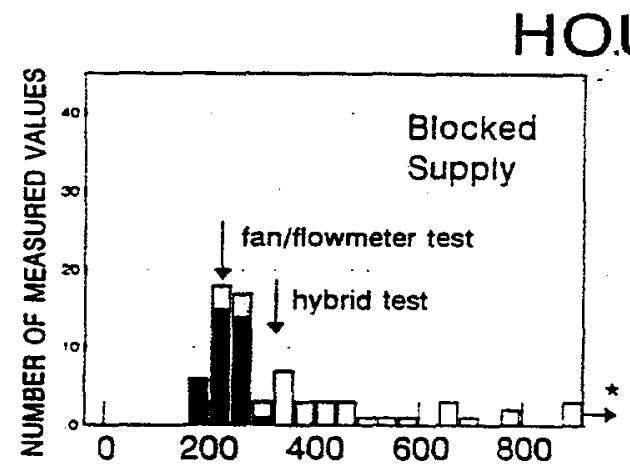

Supply Leakage, cfm

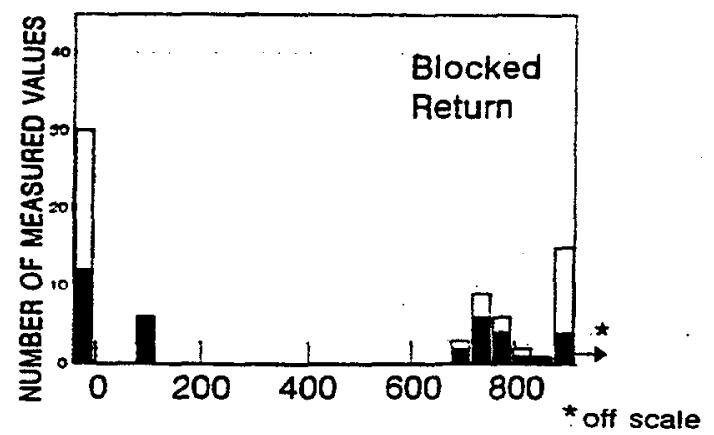

Supply Leakage, cfm

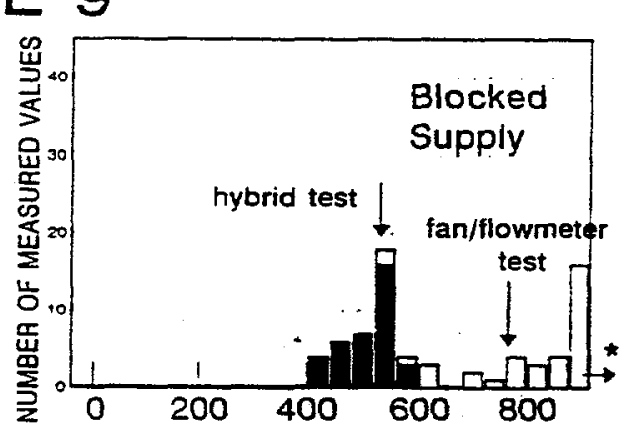

Return Leakage, cfm

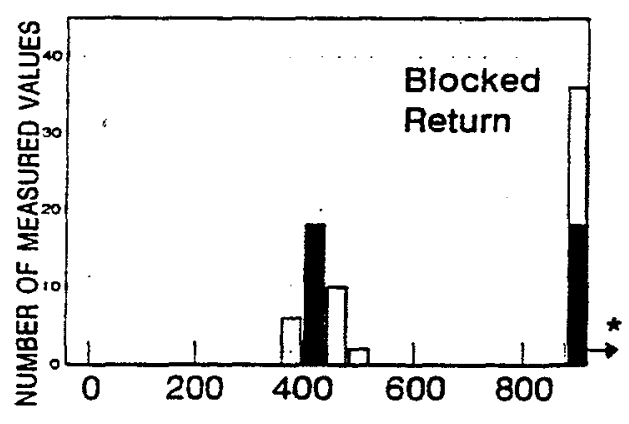

Return Leakage, cfm

Figure 4. Duct Leakage Resuits, One-Story House, $1500 \mathrm{ft}^{2}$, Ducts in Unconditioned Basement. 